\title{
Income and Education as Predictors of Stroke Mortality after the Survival of a First Stroke
}

\author{
Kozma Ahacic, ${ }^{1}$ Sven Trygged, ${ }^{2}$ and Ingemar Kåreholt ${ }^{2,3}$ \\ ${ }^{1}$ Department of Public Health, Karolinska Institutet, 17176 Stockholm, Sweden \\ ${ }^{2}$ Department of Social Work, Stockholm University, 10691 Stockholm, Sweden \\ ${ }^{3}$ Aging Research Centre, Karolinska Institutet and Stockholm University, 11330 Stockholm, Sweden \\ Correspondence should be addressed to Sven Trygged, sven.trygged@socarb.su.se
}

Received 15 December 2011; Revised 9 February 2012; Accepted 12 February 2012

Academic Editor: Halvor Naess

Copyright (c) 2012 Kozma Ahacic et al. This is an open access article distributed under the Creative Commons Attribution License, which permits unrestricted use, distribution, and reproduction in any medium, provided the original work is properly cited.

Background. It is well known that socioeconomic indicators, such as income and education, predict both stroke incidence and stroke mortality. This means that persons in lower socioeconomic positions are less likely to survive their stroke, and there will be a selective survival in the group discharged from hospital after their first stroke. Question. Does socioeconomic position continue to predict mortality, stroke specific, or from other causes, among patients surviving their first stroke in spite of this selective survival? Methods. All persons in Sweden aged 40-59 years who were discharged after a first hospitalization for stroke in 1996-2000 were included $(n=10,487)$, then followed up until the end of the fourth calendar year after discharge. Data were analysed with Cox regressions controlling for age, sex, and stroke type. Results. Persons with high socioeconomic position, measured by education and income, have lower mortality than those of low position. Education was not significant when adjusted for income, however. The risk of dying was similar for stroke-specific mortality and all-cause mortality, for those with cerebral infarction as well as for all patients. Conclusions. Socioeconomic position predicted stroke-specific mortality also in the selective group of persons who survived their first stroke.

\section{Introduction}

Many studies show that persons in lower socioeconomic positions, such as low-income groups or persons with a short education, have higher risk of dying from stroke [1-3]. This also means that persons in lower socioeconomic positions will survive a stroke to a lesser degree than persons in higher positions. Thus, among people discharged from hospital after their first stroke a selective survival will have occurred. It is moreover reasonable to assume that people who come under health care supervision may fare better, for example, due to medication and physiotherapy. In other words, it seems likely that the general access to a universal health care system and/ or selective survival may have modified the association with socioeconomic position.

Our question is whether socioeconomic position predicts stroke-specific mortality also among the selective group of patients surviving their first stroke. When death was measured as all-cause mortality, socioeconomic position did continue to play a role as persons in low socioeconomic position that survived a first stroke remained at higher risk of early mortality [4]. However, it is unclear whether the socioeconomic gradient for stroke-specific mortality is similar to that for all-cause mortality. Some studies indicate that socioeconomic position continues to predict stroke-specific mortality [5-8], but to our knowledge this specific issue has not been addressed before.

Object of This Study. To what extent does income and education predict stroke-specific mortality and mortality due to other causes after the discharge from a first hospitalization for stroke?

\section{Methods}

2.1. Study Population. This study was carried out in Sweden, where approximately 30000 persons are afflicted by stroke each year [9]. Stroke is a disease of the elderly but about 20 percent of stroke sufferers in Sweden are of working age, that is, under 65. Most hospitals are public and the few 
Table 1: Descriptive statistics $(n=10,487)$.

\begin{tabular}{|c|c|c|c|c|c|c|c|c|}
\hline & \multicolumn{4}{|c|}{ Income (quartiles) } & \multicolumn{3}{|c|}{ Education } & \multirow[b]{2}{*}{ All } \\
\hline & 1 (lowest) & 2 & 3 & 4 & Compulsory & Upper secondary & University & \\
\hline \multicolumn{9}{|l|}{ Died during the followup (\%) } \\
\hline No & 83.0 & 90.8 & 94.4 & 94.9 & 90.0 & 90.9 & 93.3 & 91.0 \\
\hline Yes, from stroke & 5.2 & 2.5 & 2.0 & 1.1 & 3.3 & 2.5 & 1.6 & 2.6 \\
\hline Yes, other cause & 11.8 & 6.7 & 3.6 & 4.0 & 6.7 & 6.6 & 5.1 & 6.4 \\
\hline \multicolumn{9}{|l|}{ Age $(\%)$} \\
\hline $40-44$ & 6.7 & 9.6 & 8.7 & 7.2 & 5.7 & 9.4 & 9.9 & 8.1 \\
\hline $45-49$ & 14.3 & 17.9 & 19.2 & 16.9 & 14.8 & 18.3 & 19.2 & 17.1 \\
\hline $50-54$ & 28.6 & 29.9 & 33.2 & 34.2 & 30.4 & 32.8 & 30.9 & 31.5 \\
\hline $55-59$ & 50.5 & 42.7 & 38.9 & 41.8 & 49.1 & 39.6 & 40.0 & 43.3 \\
\hline \multicolumn{9}{|l|}{$\operatorname{Sex}(\%)$} \\
\hline Men & 59.4 & 51.2 & 56.6 & 82.1 & 64.0 & 61.8 & 60.7 & 62.4 \\
\hline Women & 40.6 & 48.8 & 43.4 & 17.9 & 36.0 & 38.2 & 39.3 & 37.6 \\
\hline \multicolumn{9}{|l|}{ Stroke category (\%) } \\
\hline Cerebral infarction & 71.4 & 65.7 & 66.8 & 68.7 & 69.8 & 68.1 & 64.7 & 68.1 \\
\hline Subarachnoid haemorrhage & 8.7 & 15.0 & 15.4 & 12.8 & 11.6 & 13.4 & 15.4 & 13.1 \\
\hline Intracerebral haemorrhage & 12.1 & 12.7 & 12.3 & 13.2 & 11.7 & 12.6 & 14.5 & 12.6 \\
\hline Stroke, not specified (I64) & 7.7 & 6.6 & 5.5 & 5.3 & 6.8 & 6.0 & 5.4 & 6.2 \\
\hline \multicolumn{9}{|l|}{ Income 1999 (100 SEK) } \\
\hline Min & 0 & 59 & 1627 & 2361 & 0 & 0 & 0 & 0 \\
\hline Max & 57 & 1621 & 2358 & 16089 & 5335 & 8020 & 16089 & 16089 \\
\hline Median & 0 & 956 & 2022 & 2909 & 1305 & 1621 & 2394 & 1680 \\
\hline \multicolumn{9}{|l|}{ Days of inpatient care } \\
\hline Median & 11 & 10 & 9 & 8 & 10 & 10 & 9 & 9 \\
\hline No. of observations & 2,458 & 2,605 & 2,725 & 2,699 & 4,035 & 4,501 & 1,951 & 10,487 \\
\hline
\end{tabular}

private ones have contracts with the county council. A wide range of rehabilitation measures are available to stroke survivors, from acute hospital care with special stroke teams to rehabilitation clinics for both in- and outpatient care.

2.2. Inclusion Criteria. All persons in Sweden aged 40-59 who were hospitalized for the first time for stroke in 1996$2000(n=11,687)$ were identified from the national register of inpatient care. Among the population there are approximately 2.5 million persons in this age group. The stroke types cerebral infarction, subarachnoid haemorrhage, intracerebral haemorrhage, and "stroke, not specified" (ICD $10=$ I60, I61, I63, and I64) were included (both principal and secondary diagnoses). Persons with a previous ischemic heart disease (ICD $10=$ I20-I25) were excluded to avoid comorbidity as well as TIA (ICD $10=$ G45.8 and G45.9) due to less reliable data. Other data were then added, such as income and education, from a Statistics Sweden population-based data register. While 1200 stroke patients died during their hospitalization, 10,487 were later discharged (see Table 1 for descriptives). The study group consists of these cases.

Both stroke-specific mortality and mortality from other causes were analysed from the first day after discharge until the end of the fourth calendar year after the stroke. We also modelled data with 30-day case fatality from hospital admission, but the results were very similar compared to data from discharge (not shown). During the followup $n=946$ died and of those $n=277$ died from stroke. Information about cause and exact date of death is from the Swedish Cause of Death Register (ICD 10 I60-I69).

Education is measured as elementary, upper secondary, and university. Income was grouped into four equally sized quartiles. The income and education data concerned the calendar year prior to the stroke.

We used Cox regressions to analyse mortality after discharge. Results are presented as relative risks. Analyses are controlled for sex, age, age square, stroke category, days of inpatient care, and days square. Days of inpatient care was used as a proxy of stroke severity. This adjustment did not affect estimates for education and income.

The study was approved by the Regional Ethical Committee in Stockholm $(2006 / 5: 1)$.

\section{Results}

Table 1 gives an overview of the studied group, showing the distribution of sex, age groups, proportion that died, stroke category, and days of inpatient care, by income quartiles and education.

Table 2 shows the mortality risk after surviving any stroke subtype, Table 3 after the main stroke category cerebral infarction. The first three columns with results in Table 2 show the risk stroke-specific mortality and the last three columns 
TABLE 2: Relative risk of dying after a stroke $(n=10,487)$.

\begin{tabular}{|c|c|c|c|c|c|c|}
\hline & \multicolumn{3}{|c|}{ Stroke-specific mortality } & \multicolumn{3}{|c|}{ Other causes of death than stroke } \\
\hline & Model 1 & 2 & 3 & 1 & 2 & 3 \\
\hline & \multirow{2}{*}{\multicolumn{3}{|c|}{$\begin{array}{c}\text { RR } \\
(P \text { value })\end{array}$}} & \multirow{2}{*}{\multicolumn{3}{|c|}{$\begin{array}{c}\text { RR } \\
(P \text { value })\end{array}$}} \\
\hline & & & & & & \\
\hline Education & $P=\mathbf{0 . 0 0 6}$ & & $P=0.392$ & $P=0.070$ & & $P=0.313$ \\
\hline Compulsory & 1 (ref) & & 1 (ref) & 1 (ref) & & 1 (ref) \\
\hline Upper secondary & $\begin{array}{c}0.81 \\
(0.098)\end{array}$ & & $\begin{array}{c}0.89 \\
(0.384)\end{array}$ & $\begin{array}{c}1.04 \\
(0.651)\end{array}$ & & $\begin{array}{c}1.14 \\
(0.129)\end{array}$ \\
\hline University & $\begin{array}{c}\mathbf{0 . 5 4} \\
(0.002)\end{array}$ & & $\begin{array}{c}0.77 \\
(0.203)\end{array}$ & $\begin{array}{c}0.80 \\
(0.055)\end{array}$ & & $\begin{array}{c}1.06 \\
(0.652)\end{array}$ \\
\hline Income (quartiles) & & $P<\mathbf{0 . 0 0 1}$ & $P<\mathbf{0 . 0 0 1}$ & & $P<\mathbf{0 . 0 0 1}$ & $P<0.001$ \\
\hline 1 (lowest) & & 1 (ref) & 1 (ref) & & 1 (ref) & 1 (ref) \\
\hline 2 & & $\begin{array}{c}\mathbf{0 . 5 3} \\
(<0.001)\end{array}$ & $\begin{array}{c}\mathbf{0 . 5 3} \\
(<0.001)\end{array}$ & & $\begin{array}{c}\mathbf{0 . 5 8} \\
(<0.001)\end{array}$ & $\begin{array}{c}\mathbf{0 . 6 0} \\
(<0.001)\end{array}$ \\
\hline 3 & & $\begin{array}{c}\mathbf{0 . 4 2} \\
(<0.001)\end{array}$ & $\begin{array}{c}\mathbf{0 . 4 3} \\
(<0.001)\end{array}$ & & $\begin{array}{c}\mathbf{0 . 3 1} \\
(<0.001)\end{array}$ & $\begin{array}{c}\mathbf{0 . 3 0} \\
(<0.001)\end{array}$ \\
\hline 4 & & $\begin{array}{c}0.21 \\
(<0.001)\end{array}$ & $\begin{array}{c}0.22 \\
(<0.001)\end{array}$ & & $\begin{array}{c}0.32 \\
(<0.001)\end{array}$ & $\begin{array}{c}\mathbf{0 . 3 1} \\
(<0.001)\end{array}$ \\
\hline Stroke category & $P=\mathbf{0 . 0 3 3}$ & $P=0.105$ & $P=0.108$ & $P<\mathbf{0 . 0 0 1}$ & $P=\mathbf{0 . 0 0 5}$ & $P=\mathbf{0 . 0 0 5}$ \\
\hline Cerebral infarction & 1 (ref) & 1 (ref) & 1 (ref) & 1 (ref) & 1 (ref) & 1 (ref) \\
\hline $\begin{array}{l}\text { Subarachnoid } \\
\text { haemorrhage }\end{array}$ & $\begin{array}{c}\mathbf{0 . 5 3} \\
(0.008)\end{array}$ & $\begin{array}{c}\mathbf{0 . 6 0} \\
(0.031)\end{array}$ & $\begin{array}{c}\mathbf{0 . 6 0} \\
(0.033)\end{array}$ & $\begin{array}{c}\mathbf{0 . 5 6} \\
(<0.001)\end{array}$ & $\begin{array}{c}\mathbf{0 . 6 3} \\
(0.003)\end{array}$ & $\begin{array}{c}\mathbf{0 . 6 3} \\
(0.003)\end{array}$ \\
\hline Intracerebral haemorrhage & $\begin{array}{c}1.07 \\
(0.699)\end{array}$ & $\begin{array}{c}1.11 \\
(0.534)\end{array}$ & $\begin{array}{c}1.11 \\
(0.517)\end{array}$ & $\begin{array}{c}1.15 \\
(0.209)\end{array}$ & $\begin{array}{c}1.18 \\
(0.145)\end{array}$ & $\begin{array}{c}1.18 \\
(0.143)\end{array}$ \\
\hline Stroke, not specified (I64) & $\begin{array}{c}1.24 \\
(0.385)\end{array}$ & $\begin{array}{c}1.17 \\
(0.518)\end{array}$ & $\begin{array}{c}1.17 \\
(0.530)\end{array}$ & $\begin{array}{c}1.10 \\
(0.523)\end{array}$ & $\begin{array}{c}1.03 \\
(0.853)\end{array}$ & $\begin{array}{c}1.03 \\
(0.843)\end{array}$ \\
\hline
\end{tabular}

Controlling for sex, age, age square, stroke category, days of inpatient care, and days square. "Ref" is the reference category. The $P$ value to the right of the variable name shows whether the variables have made a significant contribution to the model. Results in bold have $P<0.05$.

RR: relative risk. RR > 1.0 means higher likelihood of dying.

the similar results for other causes of death than stroke. The analyses show that persons with low education and low income had higher risk for stroke-specific mortality when analysed separately (Table 2). The risk of dying was lower for persons with university education than for those with elementary education (Model 1) and was lower for persons with higher-income than for persons with lower-income (Model 2). Including both variables measuring socioeconomic position, that is, controlling for each other, only income continued to be significant (Model 3).

The relative risk of stroke-specific mortality in the highest income quartile was only about one fifth compared to the lowest quartile (RR 0.22) when adjusted for education. The table presents income quartiles in average over educational groups, although a detailed analysis suggests that the relative difference in risk was greater in the group with the shortest education.

The analyses of the risk for other causes of death than stroke showed similar pattern as stroke-specific mortality, except that education was only significant on the 10-percent level and that the mortality differences between income quartiles was slightly smaller. The highest income quartile had a mortality risk that was about a third of the lowest income quartile.
Among persons discharged from hospital the risk of dying from stroke was about half among those with subarachnoid haemorrhage as compared to the other stroke subcategories.

Table 3 displays the mortality pattern for the main stroke category cerebral infarction separately. This pattern was similar to that of all stroke subtypes except that association between education and mortality was significant for both stroke-specific mortality and mortality from other causes of death.

\section{Discussion}

Socioeconomic position, that is, income and education, predicted stroke-specific mortality-as well as mortality due to other causes-also after the selective survival of a first stroke. While education was not significant when income was included in the model, the risk of dying from stroke in the highest income quartile was one-fifth of that in the lowest income quartile.

This might indicate that economic resources are more decisive than educational ones (e.g., how well-informed someone is). However, since education generally precedes income as it is completed early in life, and income is partly 
TABLE 3: Relative risk of dying after a cerebral infarction $(n=7,143)$.

\begin{tabular}{|c|c|c|c|c|c|c|}
\hline & \multicolumn{3}{|c|}{ Stroke-specific mortality } & \multicolumn{3}{|c|}{ Other causes of death than stroke } \\
\hline & Model 1 & 2 & 3 & 1 & 2 & 3 \\
\hline & & $\begin{array}{c}\mathrm{RR} \\
(P \text { value })\end{array}$ & & & $\begin{array}{c}\mathrm{RR} \\
(P \text { value })\end{array}$ & \\
\hline Education & $P=\mathbf{0 . 0 0 7}$ & & $P=0.198$ & $P=0.006$ & & $P=0.102$ \\
\hline Compulsory & 1 (ref) & & 1 (ref) & 1 (ref) & & 1 (ref) \\
\hline Upper secondary & $\begin{array}{c}0.78 \\
(0.109)\end{array}$ & & $\begin{array}{c}0.86 \\
(0.345)\end{array}$ & $\begin{array}{c}1.08 \\
(0.448)\end{array}$ & & $\begin{array}{c}1.18 \\
(0.101)\end{array}$ \\
\hline University & $\begin{array}{c}\mathbf{0 . 4 5} \\
(0.002)\end{array}$ & & $\begin{array}{c}0.63 \\
(0.083)\end{array}$ & $\begin{array}{c}\mathbf{0 . 6 7} \\
(0.009)\end{array}$ & & $\begin{array}{c}0.90 \\
(0.486)\end{array}$ \\
\hline Income (quartiles) & & $P<\mathbf{0 . 0 0 1}$ & $P<\mathbf{0 . 0 0 1}$ & & $P<\mathbf{0 . 0 0 1}$ & $P<\mathbf{0 . 0 0 1}$ \\
\hline 1 (lowest) & & 1 (ref) & 1 (ref) & & 1 (ref) & 1 (ref) \\
\hline 2 & & $\begin{array}{c}\mathbf{0 . 4 3} \\
(<0.001)\end{array}$ & $\begin{array}{c}\mathbf{0 . 4 4} \\
(<0.001)\end{array}$ & & $\begin{array}{c}0.57 \\
(<0.001)\end{array}$ & $\begin{array}{c}0.56 \\
(<0.001)\end{array}$ \\
\hline 3 & & $\begin{array}{c}\mathbf{0 . 3 5} \\
(<0.001)\end{array}$ & $\begin{array}{c}\mathbf{0 . 3 6} \\
(<0.001)\end{array}$ & & $\begin{array}{c}0.27 \\
(<0.001)\end{array}$ & $\begin{array}{c}0.27 \\
(<0.001)\end{array}$ \\
\hline 4 & & $\begin{array}{c}\mathbf{0 . 2 0} \\
(<0.001)\end{array}$ & $\begin{array}{c}\mathbf{0 . 2 2} \\
(<0.001)\end{array}$ & & $\begin{array}{c}\mathbf{0 . 3 0} \\
(<0.001)\end{array}$ & $\begin{array}{c}\mathbf{0 . 3 1} \\
(<0.001)\end{array}$ \\
\hline
\end{tabular}

Controlling for sex, age, age square, days of inpatient care, and days square. "Ref" is the reference category. The $P$ value to the right of the variable name shows whether the variables have made a significant contribution to the model. Results in bold have $P<0.05$.

RR: relative risk. RR > 1.0 means higher likelihood of dying.

the result of educational achievements, education may be conceptualized as a factor underlying the later association between income and mortality.

While none of the previous studies specifically examines income and education as predictors of stroke mortality after the selective survival from a first stroke, some studies have had followup periods that partly overlap with ours [5-8], and although some of them have other indictors of socioeconomic position, for example, occupation [6] or looking at stroke incidence rather than mortality [10], their results point in the same direction as ours, that is, that socioeconomic position continues to be a strong predictor also after the selective survival of a first stroke. If anything, the socioeconomic gradient indicated in our results was even steeper than for stroke mortality in general [3].

That socioeconomic position predicts stroke mortality also after the selective survival from a first stroke may indicate the importance of buffering socioeconomic inequalities with secondary prevention. The utilization of health care differs by socioeconomic position also in countries with universal health coverage. In Sweden, for example, higher income groups utilize physicians to a greater extent than lower income groups [11]. Studies have also found a socioeconomic gradient for waiting time for carotid surgery [5], use of magnetic resonance imaging (MRI) [5, 12], and for receiving optimal acute care [13]. Even so, the latter study also indicates that the socioeconomic differences in stroke outcome cannot be explained by differences in acute care [13].

There are many factors besides health care utilization and medication that affect mortality risk. Disabled individuals also run an increased risk of dying from stroke [14] that may be related to income differences in disability $[12,15]$, compliance, and coping ability [16].
Health behaviour is important for both primary and secondary prevention and lower-income groups are in greater need of health behaviour counselling, for example, concerning smoking habits [17]. In one study, the socioeconomic gradient for the incidence of stroke among middle-aged persons could largely be explained by health behaviour, that is, smoking and alcohol consumption [9]. On the other hand, in a population-based Swedish study on elderly patients with cerebral infarction [18], the socioeconomic gradient persisted with adjustments for health behaviour.

In our results, the socioeconomic gradient was just slightly larger for stroke-specific mortality than for mortality due to other causes. This indicates that determinants of socioeconomic differences may be shared between stroke and other morbidity. It also indicates that in spite of the fact that we have focused on socioeconomic differences in mortality late in the disease process, that is, after surviving and being discharged from hospital after a first stroke, it is the effects of determinants further upstream that are captured.

Our results indicate the need to allocate more resources to low-income groups than to high-income groups, targeting them as a high-risk population. But it remains unclear whether the increased risk is of relatively recent origin, or whether it reflects disadvantages accumulated over a life-span, with respect to health care and health behaviour as well as to other factors.

It is worth noting that a review of the most effective evidence-based strategies for reducing health inequalities suggests interventions focused on early life and general living conditions, that is, a good start in life, that all young people should be able to maximize their capabilities and have control over their lives, fair employment, good work, and healthy standards of living for all, and healthy and sustainable 
communities, besides the role and impact of ill-health prevention [19].

Otherwise, it has been recognized that people's working conditions, such as work stress and control, are closely correlated with income differences [20-22]. Other factors may interact with socioeconomic position so that the joint exposure of such factors as health behaviour and received health care play a role for stroke mortality.

This study did not examine the effect of socioeconomic position on the risk of a first stroke or the selectivity in the survival of it. Thus, it was not able to compare risks before and after a first stroke. This might be interesting for future research.

The registers used are considered to be of high quality, but there are limitations. There are no records of stroke severity, or such traditional risk factors as smoking, obesity, and hypertension. In a recent study we described how persons of working age belonging to higher-income groups were more likely to return to paid work after a stroke [23]. This interest in the possibility to return to paid work also lays behind the age limits applied in this study.

Another limitation was the lack of information on ethnicity or comorbidity. It would also have been interesting to examine the pathway separately for men and for women, as the pattern may differ both due to different environmental influences and to different susceptibility for the disease. A separate analysis by gender was not viable because of the small number of women who died from stroke $(n=81)$. Any closer analysis of the determinants was similarly restricted due to the rather small number of deaths, and there is a possibility of bias due to omitted variables.

A complication that obscures comparability between studies is the choice of reference group, which will tend to differ along the pathway of the disease. In studies of stroke incidence the natural choice is the general population, but in studies of poststroke mortality the nonfatal cases of the disease are the obvious choice. It is unclear how the socioeconomic gradient, as well as the influence of other factors, are affected by the choice of reference group. This is an issue that deserves to be recognized and more closely studied in the future.

This study recognizes that the influence of a factor might differ depending on the stage in the pathway of the disease. An important implication of our study is that there is a need to separate the influence of different factors along the pathway from disease to death.

There is no exact boundary between when mortality risk from the first stroke ends and when the mortality risk from a second stroke should be conceived to begin. This boundary was also alternatively operationalized using 30 days from hospital admission with similar results, but there is a certain face validity in using hospital discharge as an indication of survival from the first stroke.

Conclusion. There are major socioeconomic differences in stroke mortality, also after the selective survival from a first stroke.

\section{Acknowledgments}

The project is financed by the Swedish Council for Working Life and Social Research (2008-0127). The authors thank Magnus Stenbeck for help with acquiring the data. They also wish to thank the reviewers for their valuable comments on the paper.

\section{References}

[1] A. M. Cox, C. McKevitt, A. G. Rudd, and C. D. A. Wolfe, "Socioeconomic status and stroke," Lancet Neurology, vol. 5, no. 2, pp. 181-188, 2006.

[2] A. E. Kunst, M. Del Rios, F. Groenhof, and J. P. Mackenbach, "Socioeconomic inequalities in stroke mortality among middle-aged men. An international overview," Stroke, vol. 29, no. 11, pp. 2285-2291, 1998.

[3] S. Toivanen, "Income differences in stroke mortality: a 12-year follow-up study of the Swedish working population," Scandinavian Journal of Public Health, vol. 39, no. 8, pp. 797-804, 2011.

[4] J. Arrich, W. Lalouschek, and M. Müllner, "Influence of socioeconomic status on mortality after stroke: retrospective cohort study," Stroke, vol. 36, no. 2, pp. 310-314, 2005.

[5] M. K. Kapral, H. Wang, M. Mamdani, and J. V. Tu, "Effect of socioeconomic status on treatment and mortality after stroke," Stroke, vol. 33, no. 1, pp. 268-273, 2002.

[6] C. Li, B. Hedblad, M. Rosvall, F. Buchwald, F. A. Khan, and G. Engström, "Stroke incidence, recurrence, and case-fatality in relation to socioeconomic position: a population-based study of middle-aged swedish men and women," Stroke, vol. 39, no. 8, pp. 2191-2196, 2008.

[7] G. Cesaroni, N. Agabiti, F. Forastiere, and C. A. Perucci, "Socioeconomic differences in stroke incidence and prognosis under a universal healthcare system," Stroke, vol. 40, no. 8, pp. 2812-2819, 2009.

[8] G. Zhou, X. Liu, G. Xu, X. Liu, R. Zhang, and W. Zhu, "The effect of socioeconomic status on three-year mortality after first-ever ischemic stroke in Nanjing, China," BMC Public Health, vol. 6, p. 227, 2006.

[9] National Board of Health and Welfare, "Folkhälsorapport 2009," Popular Health Report 2009, National Board of Health and Welfare, Stockholm, Sweden, 2009.

[10] H. Kuper, H. O. Adami, T. Theorell, and E. Weiderpass, "The socioeconomic gradient in the incidence of stroke: a prospective study in middle-aged women in Sweden," Stroke, vol. 38, no. 1, pp. 27-33, 2007.

[11] E. van Doorslaer, C. Masseria, and X. Koolman, "Inequalities in access to medical care by income in developed countries," Canadian Medical Association Journal, vol. 174, no. 2, pp. 177183, 2006.

[12] D. Jakovljević, C. Sarti, J. Sivenius et al., "Socioeconomic status and ischemic stroke: the FINMONICA stroke register," Stroke, vol. 32, no. 7, pp. 1492-1498, 2001.

[13] V. Langagergaard, K. H. Palnum, F. Mehnert et al., "Socioeconomic differences in quality of care and clinical outcome after stroke: a nationwide population-based study," Stroke, vol. 42, no. 10, pp. 2896-2902, 2011.

[14] G. A. M. van den Bos, J. P. J. M. Smits, G. P. Westert, and A. Van Straten, "Socioeconomic variations in the course of stroke: unequal health outcomes, equal care?" Journal of Epidemiology and Community Health, vol. 56, no. 12, pp. 943-948, 2002. 
[15] N. U. Weir, A. Gunkel, M. McDowall, and M. S. Dennis, "Study of the relationship between social deprivation and outcome after stroke," Stroke, vol. 36, no. 4, pp. 815-819, 2005.

[16] Q. Liu, M. Wang, J. Guo, J. Li, C. Li, and M. Qian, "Effect of socioeconomic status on secondary prevention of stroke," International Journal for Quality in Health Care, vol. 23, no. 4, pp. 405-412, 2011.

[17] K. Ahacic, P. Allebeck, and K. D. Thakker, "Being questioned and receiving advice about alcohol and smoking in health care: associations with patients' characteristics, health behavior, and reported stage of change," Substance Abuse Treatment, Prevention, and Policy, vol. 5, no. 1, p. 30, 2010.

[18] U. Löfmark and A. Hammarström, "Evidence for age-dependent education-related differences in men and women with first-ever stroke: results from a community-based incidence study in northern Sweden," Neuroepidemiology, vol. 28, no. 3, pp. 135-141, 2007.

[19] M. Marmot, "Fair society, healthy lives," Tech. Rep., The Marmot Review, London, UK, 2010, http://www.instituteofhealthequity.org/projects/fair-society-healthy-lives-the-marmot-review/fair-society-healthy-lives-executive-summary.pdf.

[20] S. Toivanen, "Exploring the interplay between work stress and socioeconomic position in relation to common health complaints: the role of interaction," American Journal of Industrial Medicine, vol. 54, no. 10, pp. 780-790, 2011.

[21] R. A. Karasek and T. Theorell, Healthy Work: Stress, Productivity and Reconstruction of Working Life, Basic Books, New York, NY, USA, 1990.

[22] R. Wilkinson and M. Marmot, Eds., Social Determinants of Health: The Solid Facts, World Health Organization The Regional Office for Europe, Copenhagen, Denmark, 2nd edition, 2003.

[23] S. Trygged, K. Ahacic, and I. Kåreholt, "Income and education as predictors of return to working life among younger stroke patients," BMC Public Health, vol. 11, p. 742, 2011. 


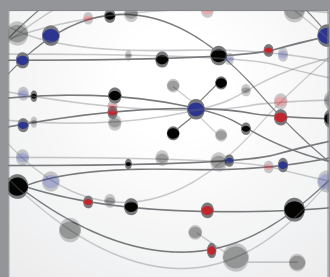

The Scientific World Journal
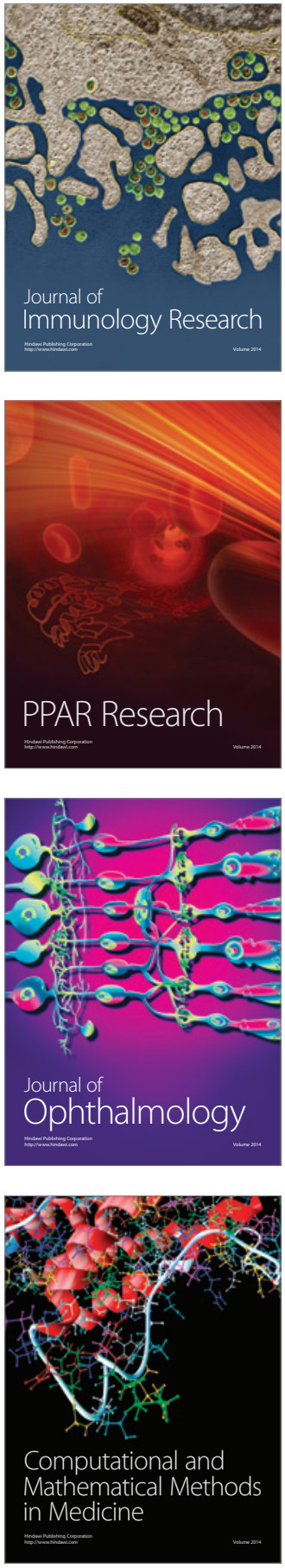

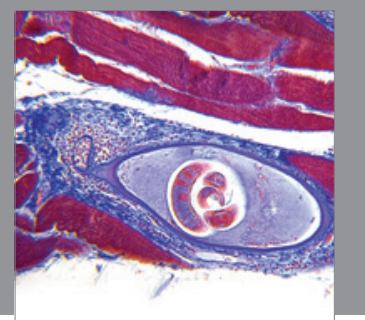

Gastroenterology

Research and Practice
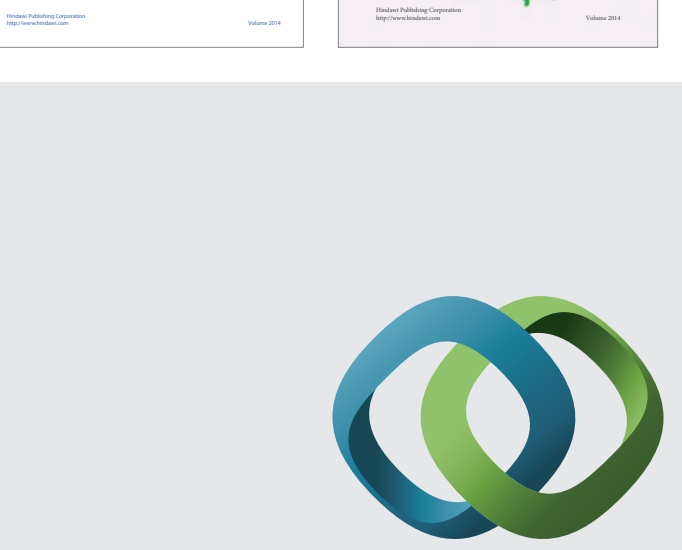

\section{Hindawi}

Submit your manuscripts at

http://www.hindawi.com
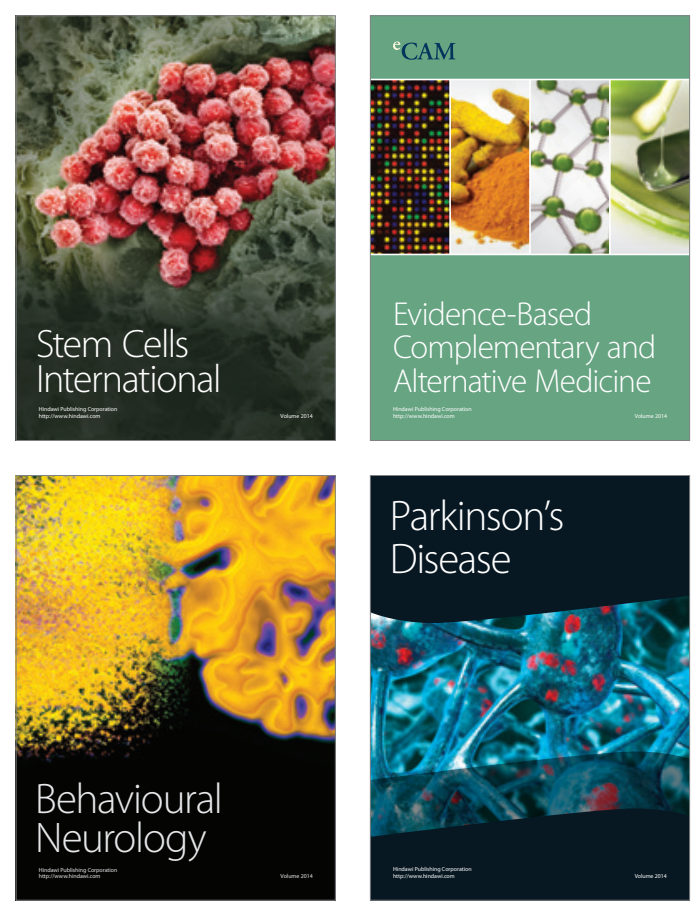

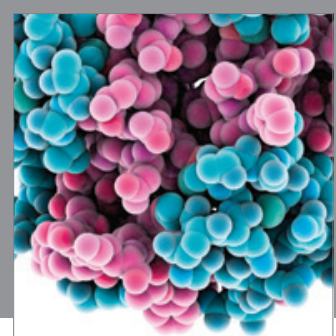

Journal of
Diabetes Research

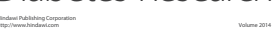

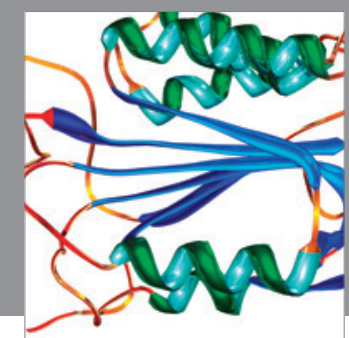

Disease Markers
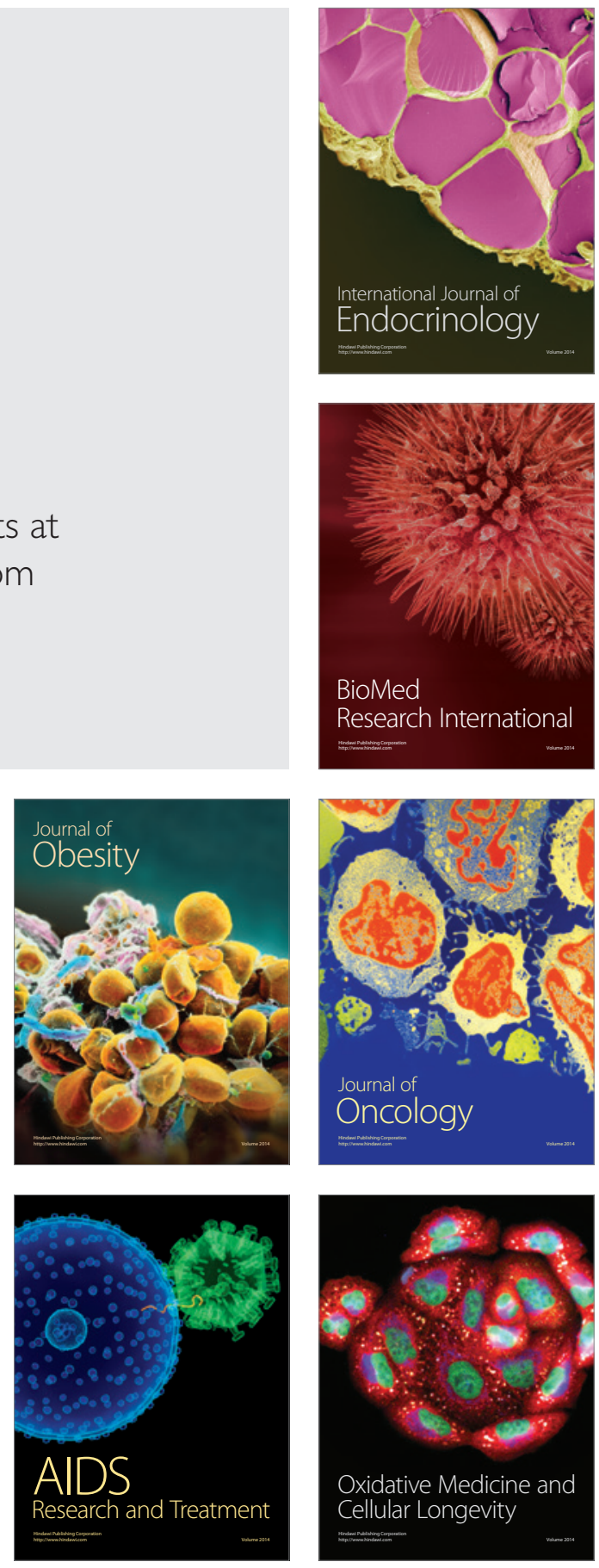